\title{
Quantification of Energy Balance during Fire Suppression by Water Mist in a Mid-Scale Test Tunnel
}

\author{
ELIZABETH BLANCHARD ${ }^{1,2}$, SYLVAIN DESANGHERE ${ }^{1}$, and PASCAL BOULET ${ }^{2}$ \\ ${ }^{1}$ CSTB \\ 84 avenue Jean Jaurès, Champs sur Marne \\ 77447 Marne-La-Vallée cedex 2, France \\ ${ }^{2}$ LEMTA Nancy Université \\ CNRS BP 70239 \\ 54506 Vandœuvre, France
}

\begin{abstract}
This paper aims at improving the understanding of the dynamics of the interactions during water mist fire suppression in tunnels. The work described here makes extensive use of numerical simulations using the Fire Dynamics Simulator (FDS, NIST), on the basis of the numerical reconstruction of an experimental test performed at one third scale. In a first step, the method consists of determining the relevant numerical parameters to accurately model the water mist using current FDS sub-models. The second step consists of calibrating the code, in order to get the best achievable numerical processing of the test. Finally, the third part of the work is devoted to the extraction and the post processing of information from the FDS calculation, in order to quantify the global energy balance within the test tunnel. This makes it possible to evaluate the distribution of energy and notably the heat absorbed by droplets during water mist application. An estimation of the efficiency of the water application is then proposed. On the whole, this paper gives an example of the use of a numerical model to help interpreting experimental results by getting information whose measurement is very difficult to reach.
\end{abstract}

KEYWORDS: tunnel fires, suppression, water mist, heat transfer, FDS, numerical modeling.

\section{NOMENCLATURE LISTING}

$\begin{array}{ll}C_{p} & \text { specific heat }\left(\mathrm{J} \cdot \mathrm{kg}^{-1} \cdot \mathrm{K}^{-1}\right) \\ h & \text { heat transfer coefficient }\left(\mathrm{W} \cdot \mathrm{m}^{-2} \cdot \mathrm{K}^{-1}\right) \\ E & \text { enthalpy }\left(\mathrm{W} \cdot \mathrm{kg}^{-1} \cdot \mathrm{m}^{3}\right) \\ L_{v} & \text { latent heat of vaporization }\left(\mathrm{J} \cdot \mathrm{kg}^{-1}\right) \\ m & \text { mass }(\mathrm{kg}) \\ Q & \text { heat flux }(\mathrm{W}) \\ S & \text { surface area }\left(\mathrm{m}^{2}\right) \\ T_{o} & \text { ambient temperature }(\mathrm{K}) \\ T & \text { temperature }(\mathrm{K}) \\ t & \text { time }(\mathrm{s}) \\ v & \text { velocity }\left(\mathrm{m} \cdot \mathrm{s}^{-1}\right)\end{array}$

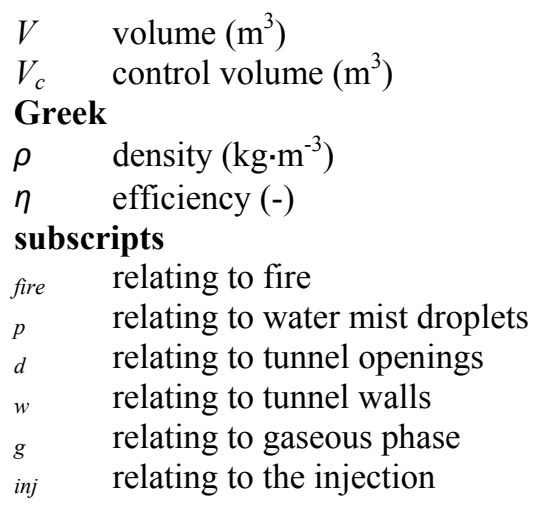

\section{INTRODUCTION}

The use of water for fire suppression and extinguishment is widespread because water is inexpensive, easy to use and is not hazardous to people and the environment. Today, there exist many ways to produce water droplets intended to be thrown over a fire, the most popular being sprinkler systems. The different techniques involved to produce droplets induce a wide range of droplets size (from several micrometers to one millimeter or more). Among these approaches, we focus here on systems producing the smallest droplets, also called 'water mist' systems. Water mist is commonly defined quantitatively by putting an upper limit on the size of droplets [1]. The use of water mist has grown at a very high rate, starting with the need to find an alternative to the banned halogen-based fire suppressing agents. The generation of fine water droplets offers a number of potential advantages over conventional sprinkler systems. The main difference comes from the fact that breaking water into a cloud of very small droplets greatly increases the surface area available for exchanging heat between water and surrounding gases, see Refs. [2,3]. 


\section{Water Mist Interaction with Fire Environment}

There are three major mechanisms related to the presence of small water droplets in the vicinity of a fire. Firstly, a significant amount of heat is transferred from the gases to the water droplets to increase their temperature up to the boiling point, then to evaporate them. This 'heat sink' results in a strong temperature decrease which helps reducing the intensity of combustion reactions. Secondly, the phase change from liquid to vapor induces a high volumetric expansion rate consisting of water vapor gas. This phenomenon prevents the mixing between fresh air and combustible vapor, acting like an inerting gas, thus reducing once again the intensity of combustion reactions. Thirdly, if they are small enough, water droplets strongly interact with thermal radiation emitted by the fire, the tunnel surfaces and the surrounding hot gases by absorption and scattering effects [4]. Water mist then acts as a radiative shield between the flames and the exposed objects [5].

However, it is not easy to get the best of water mist for a given application. Indeed, very small droplets have low initial momentum, so that they are rapidly decelerated after leaving the nozzle, reducing their ability to penetrate the flame zone [6] and making it difficult to steer them towards a given target. The complicated flows generated by water mist flooding on one hand and by fire on the other hand are particularly difficult to handle. From the numerical point of view, advanced modeling techniques like CFD models are required to evaluate water droplet movement in the fire environment. A fraction of the water injected falls to the ground or drips over the walls [7]. It is therefore interesting to define the efficiency of water application by evaluating the amount of water which really plays a part in fire suppression. This could help making a choice between several water mist system designs (different flow rates, location of nozzles, etc.), by drawing in parallel the corresponding surrounding conditions (air temperature, heat flux, etc.).

\section{The Use of Water Mist in Tunnels}

Fire is a significant threat to safety in tunnels and constitutes an important risk of operating losses. Recent major fires in the last decades stress the need for a better care to fire safety management in underground facilities [8]. In this context, water mist appears as a promising technique to get a breakthrough in fire suppression and extinguishment. The potential heat release rates of fires in tunnels are very high [9]. The resulting fire conditions can be so severe that manual fire fighting operations is impossible. In this case, water flooding appears to be the ultimate direct action to fight the fire. At the same time, the radiation reduction offered by water mist could be very useful to prevent fire extension to other vehicles trapped in the tunnel.

A relevant operating of water mist systems in tunnels requires better understanding of interaction between underlying phenomena that occur during a suppressed tunnel fire. This stresses the need for experimental data sets aimed at producing reliable validation cases, especially for numerical modeling purposes. However, the understanding of phenomena induced by water mist application is still at an early stage and most of the experiments were carried out at laboratory scale (see for example Ref. [10]). Up to now, a large part of experimental and numerical works mainly focuses on relatively fundamental phenomena, using simplified test configurations, see for example Refs. [6,11].

A few real-scale tunnel fire experiments have been conducted in the past, like the EUREKA program [11], the US Memorial Tunnel campaign [13], or the UPTUN project [9]. Such real-scale tests are very expensive because a large number of sensors are required to get a detailed measurement of velocity and temperature fields. In such tests, smoke and hot gases are traditionally tracked only by recording vertical temperature profiles at several distances from the fire. An alternative way is to study tunnel fire at a reduced scale. The use of a reduced-scale experimental tunnel has several assets, among them the ability to better characterize the flows and the thermal environment induced by fire, while maintaining reasonable costs.

The present work uses a one third-scale test tunnel. This reduced scale experimental configuration $\left(1 / 3^{\text {rd }}\right)$ has been built with the aim of studying fire phenomena in a more realistic way than with laboratory scale $\left(1 / 20^{\text {th }}\right)$ and in a more affordable way than with real-scale experiments [14]. On the basis of a test campaign conducted in this tunnel, the use of a CFD code allows quantifying phenomena involved in tunnel fire and even when water mist system is activated. In this way, this work proposes a definition for water mist system efficiency. 


\section{TUNNEL TEST DESCRIPTION}

\section{Test Set-Up}

The mid-scale tunnel is $43 \mathrm{~m}$ long with a semi-circular cross-section around $4 \mathrm{~m}^{2}$ and a $2.2 \mathrm{~m}$ hydraulic diameter (see Fig. 1). Walls are covered by fire resistant mortar cement whose thermal characteristics are known. Floor is made of concrete.

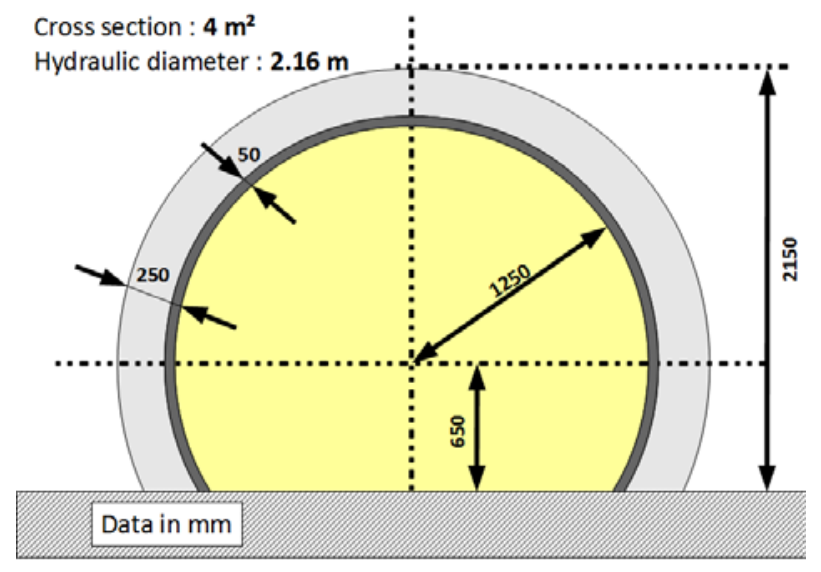

Fig. 1. Cross-sectional view of the tunnel (data in $\mathrm{mm}$ ).

188 sensors are set up in the test tunnel. They are located on four sections upstream, seven sections downstream and one at the fire location (see Fig. 2). The use of so many sensors allows characterizing the environment on several whole tunnel sections. The measurements include air temperature and velocity, fuel mass, heat flux and air composition $\left(\mathrm{CO}_{2}\right.$ and $\mathrm{O}_{2}$ concentration).

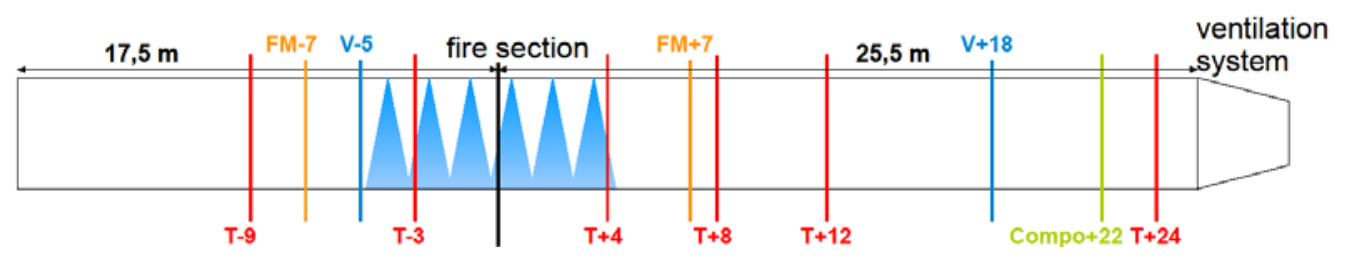

Fig. 2. Position of measurement sections (T: temperature, V: air velocity, FM: heat flux and Compo: air composition). Nozzle locations are represented by blue sprays. Numbers are distances in $\mathrm{m}$.

\section{Longitudinal Ventilation}

A ventilation system is mounted at the downstream side of the tunnel. It allows controlling the longitudinal air flow, by extracting a roughly constant gas volume flux. The purpose of the experimental campaign was to study two ventilation regimes, one below and one above the critical backlayering velocity (i.e. the longitudinal velocity above which all the combustion gases are transported downstream the fire). Considering the predicted fire heat release and the tunnel dimensions, the critical value has been estimated between 1.2 and $1.8 \mathrm{~m} / \mathrm{s}$, depending on the correlation used to estimate it [15]. The test discussed in the present paper has been performed with an exhaust volume flux corresponding to a longitudinal velocity around $3.0 \mathrm{~m} / \mathrm{s}$. Consequently, this value induces an over-critical ventilation regime without smoke backlayering upstream the fire.

\section{Fire Load}

The test is conducted with a fire load produced by a $1 \mathrm{~m} \times 0.5 \mathrm{~m} \times 0.1 \mathrm{~m}$ heptane pool. Liquid fuel has been chosen in order to ensure repeatability between experiments and to reduce uncertainties related to estimation of heat release rate the (HRR). The HRR is deduced from fuel weight loss monitoring and by oxygen consumption monitoring [16]. As shown on Fig. 3, the HRRs deduced with the two methods are almost the same before water mist system activation. After that, deduced HRRs are clearly different. This 
may be due to the water spray above the fire that disturbs the heptane pool weight monitoring. The test duration corresponds to the complete burning of initial heptane quantity.

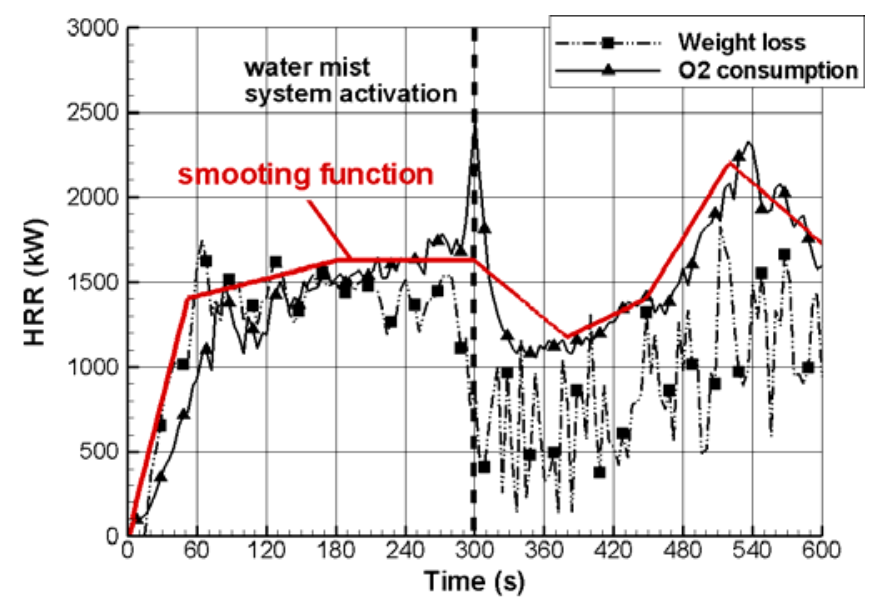

Fig. 3. HRR deduced from fuel weight loss and oxygen consumption. The smoothing function used as input in the simulation is also presented.

This test has been chosen for the present study because it is characterized by a very low injected water flow rate (as described in the next paragraph). The main consequence is that HRR reaches a higher value during the mitigation period (300-600 s) than at the activation time $300 \mathrm{~s}$. Consequently, mitigation does not induce an important gas cooling. It also allows well studying the fire environment when the mitigation system is activated. For information, during the test campaign in the midscale tunnel, one test was performed in similar conditions than the present test but with a higher number of nozzles ( 14 nozzles). Fire was also suppressed in less than 1 min which does not allow studying surrounding conditions during mitigation.

\section{Water Mist System}

The water mist system is composed of six nozzles located on the same row on the centre line of the tunnel. Nozzles are located between $4 \mathrm{~m}$ upstream and $3.5 \mathrm{~m}$ downstream the fire location, $1.5 \mathrm{~m}$ apart one other (see Fig. 2). The operating pressure is around 90 bars. The water flow rate injected at each nozzle is close to $5.5 \mathrm{~L} / \mathrm{min}$, corresponding to a total mist discharge rate around $33 \mathrm{~L} / \mathrm{min}$. All the nozzles are manually activated at the same time, $300 \mathrm{~s}$ after ignition.

\section{TUNNEL TEST SIMULATION}

\section{Numerical Tool Description}

The present work makes use of the Fire Dynamics Simulator (FDS, developed by NIST, USA (see [17] and [18])), which is a 3-D CFD model designed to simulate low-speed, thermally-driven flows. This numerical tool is widely used in the fire community, generally to evaluate fire consequences in buildings. FDS has also been used to simulate tunnel fires, especially by McGrattan and Hamins [19], Cochard [20] and Mawhinney and Trelles (see [21] and [22]). The ability of current version of FDS to reconstruct the fire environment from a test performed within the one third test tunnel used here (with a longitudinal velocity too low to prevent back-layering effect and without water mist application) has been presented in details in [15]. This paper shows that agreement between FDS predictions and temperature measurements is pretty good at different distances from the fire. Air flows are also well reproduced in the simulation, the difference with measurement staying within the overlapping uncertainty limits.

Concerning spray modeling, FDS uses an Eulerian-Lagrangian approach to simulate the turbulent transport of evaporating droplets. This means that trajectories of water droplets are individually tracked. In order to reduce the computational cost, only a limited number of droplets are tracked. Each droplet in the calculation is assumed to represent many others of similar size and trajectory. The droplets tracked have to constitute a representative sample of the entire spray. The spray characteristics are defined at the injection 
point by a considerable number of parameters such as fluid thermal properties, droplet size distribution and injection features (spray pattern, volumetric flow rate, etc.). In particular, the droplet size distribution is represented by a probability function that describes the fraction of the water volume transported by droplets whose dimension is less than a given diameter. In FDS, the default probability function is a combination of log-normal and Rosin-Rammler distribution. Droplets trajectories are calculated by solving the momentum conservation. Heat transfer between the droplets and the surrounding gas is computed using correlations preserving the equilibrium with gaseous phase inside each grid cell. When a particle strikes an obstacle, it sticks it (new speed and direction are reassigned) until to be evaporated.

\section{Input Data Definition}

The mid-scale tunnel test has been simulated with the FDS code version 5.4.0. The computational domain includes the tunnel, the ventilation system at the downstream side (by setting an exhaust volume flow), and a free area at the upstream side. The last area is modeled in order to better promote the flow turbulence within the tunnel. Cubic grid cells of $10 \mathrm{~cm}$ are employed to discretize space and the unit sphere is divided into 500 solid angles to solve the radiative transfer equation.

The main input data for the numerical simulation are the HRR curve, the extraction volumetric flow rate and the global combustion reaction. A HRR sensitivity analysis has been performed in order to calibrate a smoothing function from experimental heptane pool weight loss and oxygen consumption monitoring. After water mist activation, HRR is deduced only from experimental oxygen consumption because fuel weigh is altered by droplets accumulated in the pool. The effect of water mist application on the heptane burning rate is represented by the experimental HRR curve. For this reason, FDS fire suppression model is not activated. HRR defined as input is plotted on Fig.3. The extracted gas volume flux at the downstream side is set to get a longitudinal velocity without fire around $3.0 \mathrm{~m} / \mathrm{s}$. Parameters defining the heptane combustion reaction (such as soot and carbon monoxide yields) are extracted from Ref. [23].

\section{Lagrangian Particle Sub-Model Calibration}

Each nozzle installed in the midscale tunnel consists of four side injectors and one central injector (see Fig. 4). The orifice diameter of all injectors is around $0.5 \mathrm{~mm}$. According to the above mentioned water flow rate, an initial velocity of $60 \mathrm{~m} / \mathrm{s}$ is assumed. Each solid spray pattern is conic and the ejection angle has been evaluated as $20^{\circ}$.

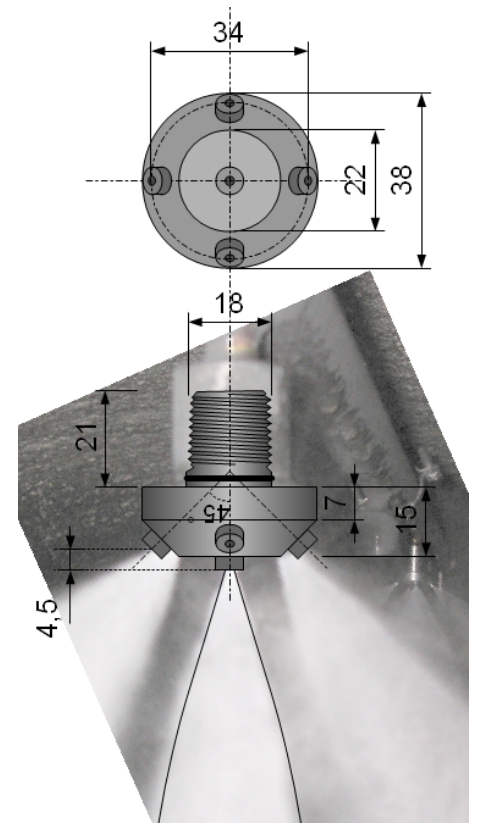

Fig. 4. Nozzle geometrical characteristics.

Spray characterization has been performed by Centre d'Etudes des Tunnels (CETU) by Phase Doppler Analysis (PDA) [24]. A description of the PDA technique is given in [6]. Droplet size has been determined 
at five positions along the central axis 4 to $50 \mathrm{~cm}$ from the injection point. As shown in Fig. 5a, measurements only concern the central spray. In the present study, it is also assumed that sprays produced by the side injectors are similar to the central one.

To calibrate the Lagrangian particle sub-models, PDA analysis has been simulated with FDS code, by varying mean diameter at the injection point from 20 to $60 \mu \mathrm{m}$. The spray is injected in a closed room and the nozzle is located at a central position of the room, represented by five injection points.

FDS prediction and experimental measurement are then compared. At each location, the spray is characterized by the mean Sauter diameter which is by definition the ratio of the volume of a sample of droplets to the surface area of the same sample.

Fig. $5 \mathrm{~b}$ presents the comparison between simulations and measurements. The best agreement appears to be obtained with the spray defined at the injection point with a hybrid law defined by a mean diameter and a Rosin-Rammler dispersion parameter equal to $40 \mu \mathrm{m}$ and 2.85 respectively. The measurement at $4 \mathrm{~cm}$ is not taken into account because the authors consider that the atomization may not yet be completed.

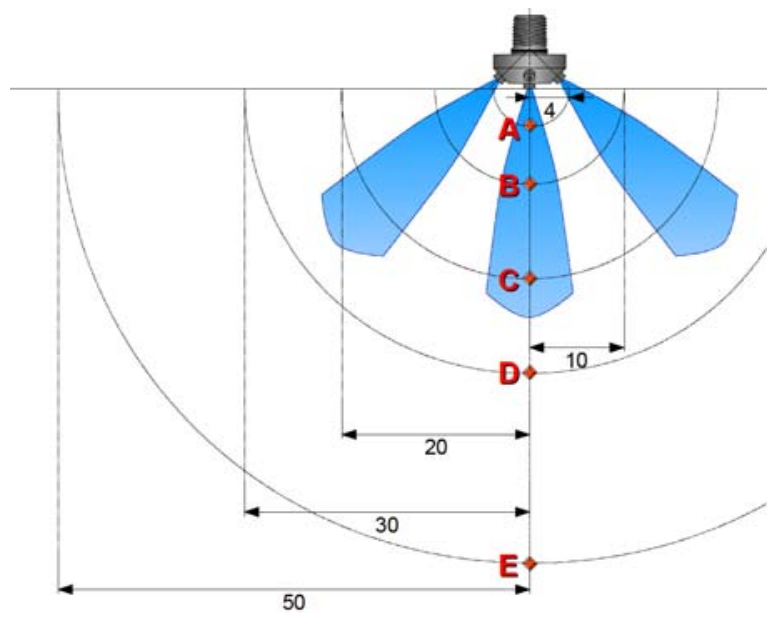

(a)

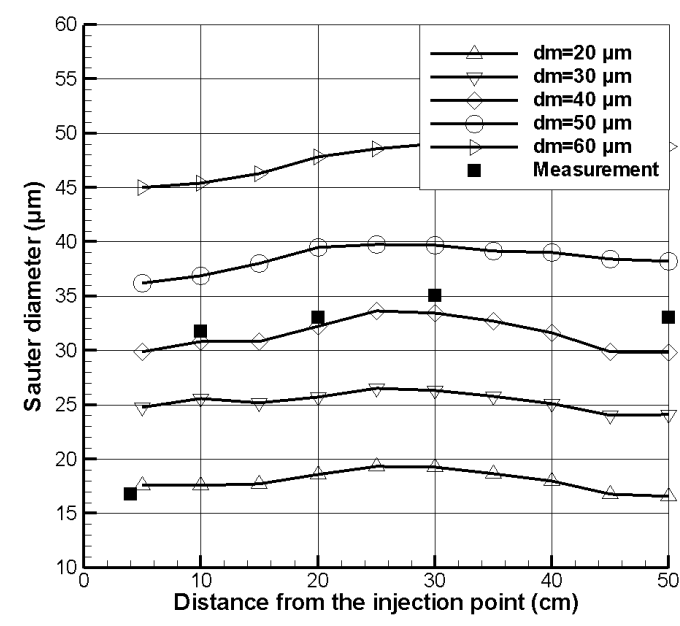

(b)

Fig. 5. Droplet size characterization: (a) location of droplet size measurement in PDA; (b) predicted (solid line) and measured (point) droplets size along the central vertical axis.

\section{COMPARISON BETWEEN MEASUREMENTS AND PREDICTED VALUES}

This stage consists in evaluating the discrepancy between predicted and measured quantities. Moreover, it allows calibrating the CFD model in order to get the best achievable numerical processing of the test.

Comparison between predicted and measured values is based upon air temperature and heat flux. During the water mist application, heat fluxes measured downstream the fire location are not interpreted since water droplets likely deposit on the radiometer and skew the measurement.

\section{Temperature}

The comparison of temperature evolutions in Fig. 6 illustrates that the model predicts the thermal conditions well. Before the mitigation system activation, the comparison of predicted temperatures to measurements shows a good general agreement at most of the locations: the slope and the magnitudes are similar. More precisely, farther the measurement section from the fire is, better the numerical accuracy is. In fact, temperature tends to be under-predicted in the flame region. The bigger discrepancy is measured at mid-height in the mixing zone between the hot smoke layer in the upper part and the fresh air in the lower part. This area is better predicted by reducing the grid cell size but the corresponding computational time is very long. The numerical data being considered as sufficiently close to measurements, the refined grid is not used in the present study. 
After the water mist system is activated, the gaseous phase is cooling. Air temperatures go down and become more uniform over the measurement section. The homogeneity in the air temperature over each measurement section highlights a thermal destratification. At all locations, the temperature decreases and its evolution after water mist activation is closely reproduced in the simulation, even when HRR increases again around $540 \mathrm{~s}$. By the end of the simulation, predicted and measured conditions correlate quite well. Whereas fire heat value changes, air temperature is almost constant between 340 and $480 \mathrm{~s}$.

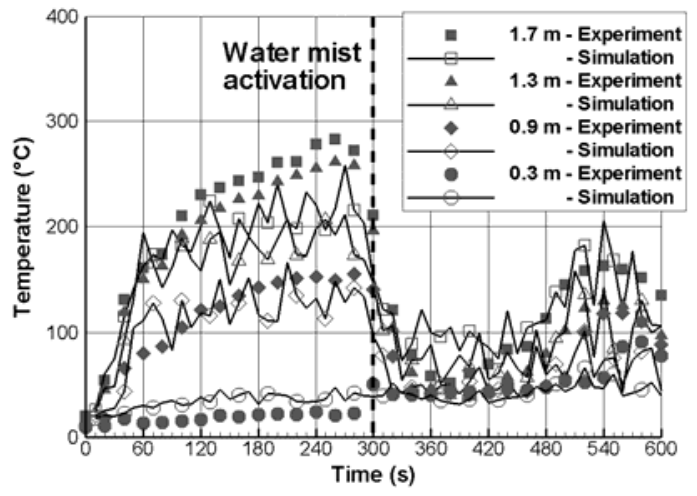

(a)

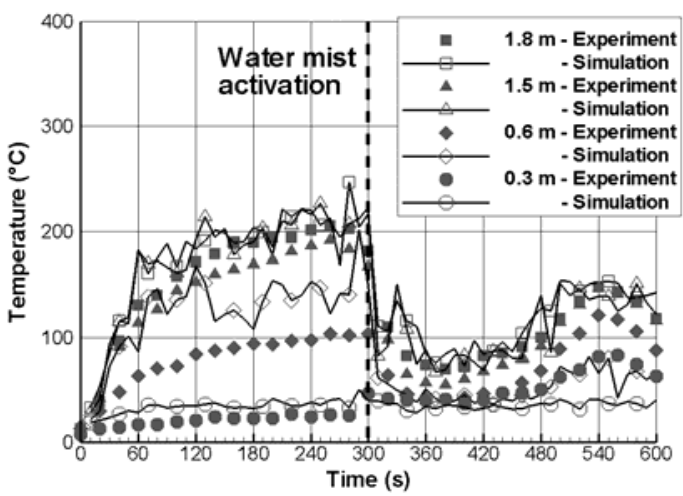

(b)

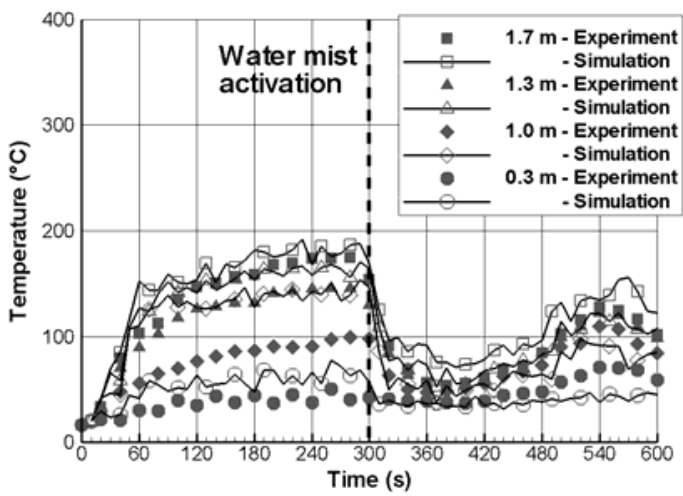

(c)

Fig. 6. Predicted and measured temperatures on the vertical centerline of three measurement sections (point for experimental data and solid line for simulation): (a) $8 \mathrm{~m}$ downstream the fire location; (b) $12 \mathrm{~m}$ downstream the fire location; (c) $24 \mathrm{~m}$ downstream the fire location.

The agreement can be defined as the arithmetic average between 20 and $300 \mathrm{~s}$ of relative difference between predicted and measured temperatures in all positions. It is around $17 \%$.

\section{Heat Fluxes}

The heat flux measurements are compared with calculations on Fig. 7 at different vertical positions, $7 \mathrm{~m}$ upstream and $7 \mathrm{~m}$ downstream the fire. Upstream the fire, heat flux are very well captured by the CFD code. The absolute difference is below $0.17 \mathrm{~kW} \cdot \mathrm{m}^{-2}$. Downstream the fire, a higher heat flux is estimated by the code. Higher the radiometer is located, bigger the discrepancy is. This could be attributed to first the poor quality of heat flux measurement in hot smoke which is partly constituted of water vapor and soot and can also alter the measurement and secondly to the extreme measurement conditions for the radiometers, the air temperature exceeding $200^{\circ} \mathrm{C}$. This could also explain the lower value measured at the higher location comparing to others $7 \mathrm{~m}$ downstream. Moreover, these figures show that predicted heat fluxes are fluctuating during the test duration compared to measurements. This difference may be attributed to measurement acquisition (every $20 \mathrm{~s}$ ) that inevitably filters out the signal. 


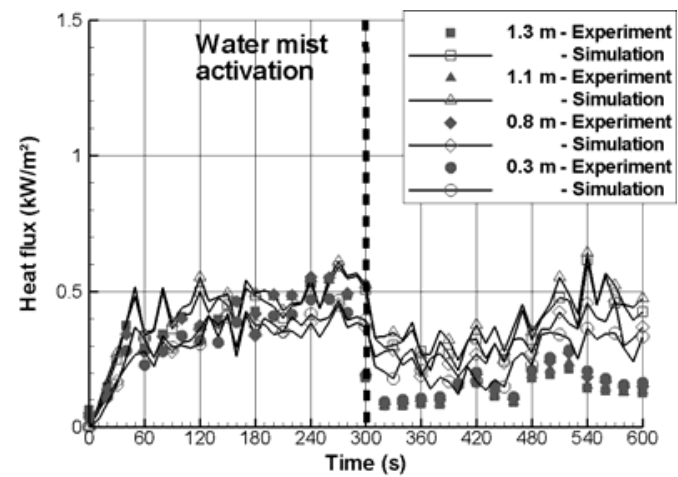

(a)
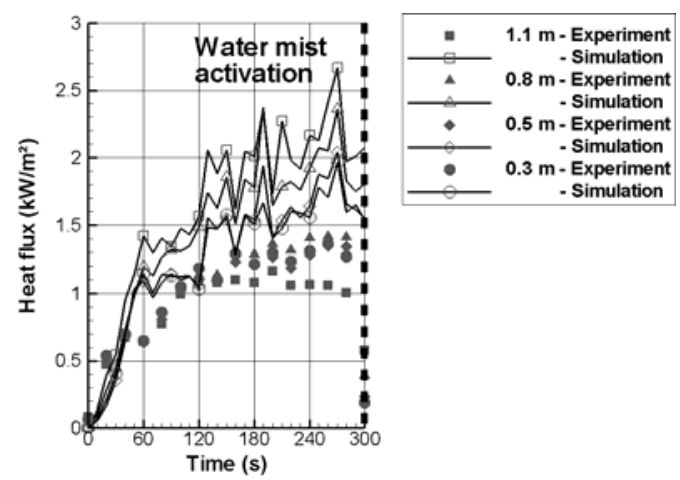

(b)

Fig. 7. Predicted and measured heat flux on the vertical centerline of two measurement sections (point for experimental data and solid line for simulation): (a) $7 \mathrm{~m}$ upstream the fire location; (b) $7 \mathrm{~m}$ downstream the fire location.

\section{EFFECT OF WATER MIST ON ENERGY BALANCE}

\section{Theoretical Background}

Global energy balance with and without water mist can be computed for the whole tunnel by extracting and collecting information from FDS calculation by adding a subroutine in the dump file. This subroutine does not touch the physical sub-models, it allows to extract additional outputs that are not a part of the official FDS version. Conservation of energy holds that the fire heat release $Q_{\text {fire }}$ :

- goes to heat the gases within the domain, noted $Q_{g}$,

- $\quad$ is transferred to boundaries by radiation and convection, noted $Q_{w}$,

- $\quad$ is transported through the openings, noted $Q_{d}$,

- $\quad$ is absorbed by the droplets (see Fig. 8).

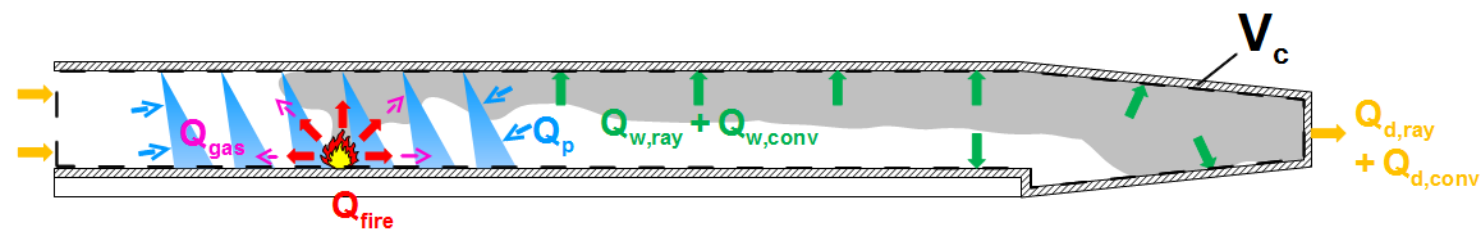

Fig. 8. Global energy balance in the midscale tunnel.

Conservation of energy can be expressed as:

$Q_{\text {fire }}=Q_{\text {gas }}+Q_{w}+Q_{d}+Q_{p}$

Quantity $Q_{g}$ is the energy required for raising the gas temperature from ambient to $T_{g a s}$ in the control volume $V_{c}$. It is related to the time derivative of the enthalpy of the gases such as:

$Q_{g a s}=\partial\left(\rho_{g} E\right) / \partial t=\partial\left(\rho_{g} C_{v, g} T_{g} V_{c}\right) / \partial t$

Concerning walls, energy is transferred by radiation, $Q_{w, \text { ray }}$ and by convection, $Q_{w, c o n v}$. The first part is defined as the difference between the incident radiative flux to the wall and the radiation emitted by the wall itself. The convective part is proportional to the difference of temperature between the gaseous phase $T_{\text {gas }}$ and the wall $T_{w}$. Thus,

$Q_{w}=h_{w, g}\left(T_{w^{-}} T_{g}\right) S_{w}+Q_{(\text {ray,incident })}-Q_{(\text {ray,emitted })}$ 
where $h_{w, g}$ is the heat transfer coefficient between the gas and the wall. The terms $Q_{\text {(ray,incident) }}$ and $Q_{(\text {ray,emitted })}$ are the radiative energy incident and emitted by the wall respectively.

In the same manner, total heat loss through the openings, transferred by radiation, $Q_{d, r a y}$, and by convection, $Q_{d, c o n v}$ is given by:

$Q_{d}=Q_{d, \text { conv }}+Q_{d, \text { ray }}=\left(C_{p, g} \rho_{g} v_{g} T_{g} A_{d}\right)_{\text {outcoming }}-\left(C_{p, 0} \rho_{0} v_{g} T_{0} A_{d}\right)_{\text {incoming }}+Q_{d, \text { ray }}$

where $Q_{d, \text { ray }}$ is equal to the radiative heat flux incident to the last grid cell before the opening.

The contribution of water mist can be expressed in two different ways, either in terms of energy absorbed from gaseous phase and tunnel walls:

$Q_{p}=h_{p, g}\left(T_{p}-T_{g}\right) S_{p}+Q_{r a y, p}+Q_{p, w}$

$Q_{r a y, p}$ is the radiative heat flux absorbed by the droplets and $Q_{p, w}$ gives the cooling energy of a solid surface by droplets. The heat loss to the openings due to droplets that go outside the computational domain appeared negligible in the present work. It is also ignored in the global energy balance.

The water mist contribution could also be expressed as the vaporized and heated water quantity in contact with gaseous phase and tunnel walls such as:

$Q_{p}=L_{v} \partial\left(m_{p, \text { evap }}\right) / \partial t+\partial\left(\rho_{p} C_{p, p} T_{p} V_{p}\right) / \partial t$

where $m_{p, \text { evap }}$ is the evaporated water quantity.

\section{Validation and Verification}

The energy balance has been assessed first in compartment fire test, without mitigation system. One test taken from a series of experiments conducted by NIST and NRC has been used (see [25] and [26]). The compartment is $7 \mathrm{~m}$ wide, $22 \mathrm{~m}$ long and $4 \mathrm{~m}$ high, with a single open door. The test involves a hydrocarbon spray fire with a $1140 \mathrm{~kW}$ heat release rate. The steady state period of this test has been simulated with the modified FDS version. The calculation has predicted an energy balance similar to that found from experimental data. As shown by Fig. 9, nearly $68 \%$ of the fire energy went to heat compartment surfaces, $32 \%$ of the energy goes into heating of the gases. In comparison with experimental data, the energy required for raising the gas temperature is lower because the simulation reproduces a steady state. The derivative of the enthalpy of the gases tends consequently to zero.

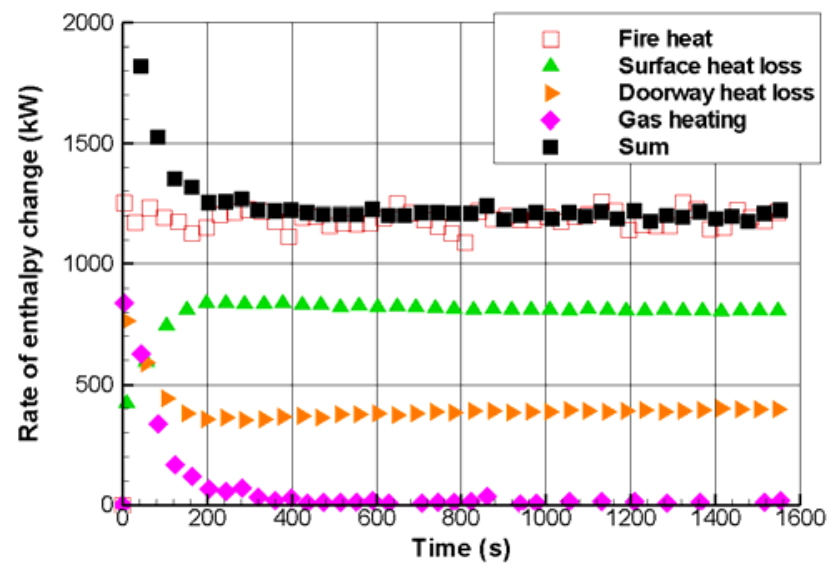

Fig. 9. The rate of heat loss to surfaces $(\Delta)$, through the doorway $(\triangleright)$, accumulated by heating the gas $(\diamond)$ and their sum ( $\square)$ as a function of time. For comparison, the calorimetric heat release rate measurement $(\square)$ is also shown. 
Even if the energy balance with water mist contribution has not been assessed with such experimental data, the authors lend confidence in it because it has led a relevant conservation of energy in few configurations involving fire or not. For instance, the verification case "water evaporation_1" which is available in the FDS library has been run. It involves stationary water droplets in a box with dimensions of $1 \mathrm{~m}$ on a side. The initial air temperature is $200{ }^{\circ} \mathrm{C}$, the median volumetric diameter of the droplets is $200 \mu \mathrm{m}$, the water temperature is $20^{\circ} \mathrm{C}$, and the total mass of water droplets is $0.01 \mathrm{~kg}$. The initial mass fraction of water vapor is 0 .

The corresponding energy balance is reported on the following figure. Because radiation is turned off, there is no fire and walls are adiabatic, only two quantities are not equal to zero: the rates of heat loss for cooling the gas and for heating (and evaporating) the water fog. The rate of heat loss for cooling the gas is plotted on Fig. 10 instead of that one for heating the gas to get positive values. The figure illustrates that the energy balance is well described between gaseous phase and water fog.

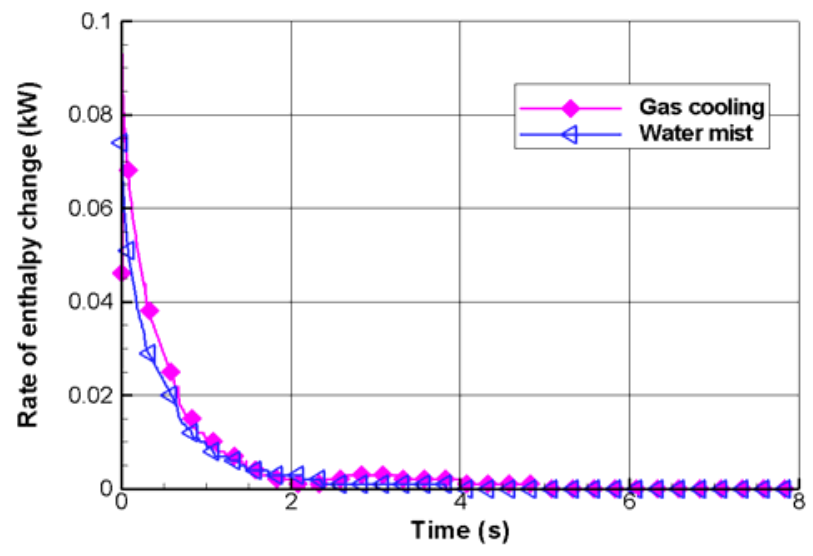

Fig. 10. Energy balance applied to 'water evaporation' verification case.

\section{Test Tunnel Application}

Figure 11 illustrates this global energy balance in our tunnel test as a function of time. Before water mist system activation, the energy balance highlights that nearly the half quantity of fire heat is lost toward tunnel walls, mainly by radiation. The remaining heat goes into heating of the gases. For comparison, the heat release rate is also shown on this figure. Besides, energy can be considered as conserved in the control volume because the sum of wall loss, opening loss and energy is equal to fire heat.

In comparison with a test conducted with a sub-critical ventilation regime, the energy balance is totally different. In fact, in this case, roughly $2 / 3$ of the heat released was dissipated through exchanges with the wall [15]. A complete study on the relation between energy balance distribution and longitudinal ventilation regime is detailed in [27]. It shows that energy balance strongly differs with the ventilation regime for two main reasons. It may be first attributed to the back-layering phenomenon which increases the surface area in contact with hot smoke in tunnel and consequently heat exchanges between walls and gaseous phase. Secondly, it has also been attributed to the influence of longitudinal ventilation on the air temperature downstream the fire location: increasing the longitudinal ventilation velocity promotes mixing of hot smoke in the upper part with fresh air in the lower part.

After water mist system activation, water droplets are introduced into the fire environment inducing gas and surface cooling and radiation attenuation. The energy balance, plotted on Fig. 11b, yields that roughly the half quantity of fire heat is absorbed by droplets. The remaining quantity goes to heat tunnel surface $(24 \%)$ or is conveyed by hot gases out of the tunnel (33\%). 


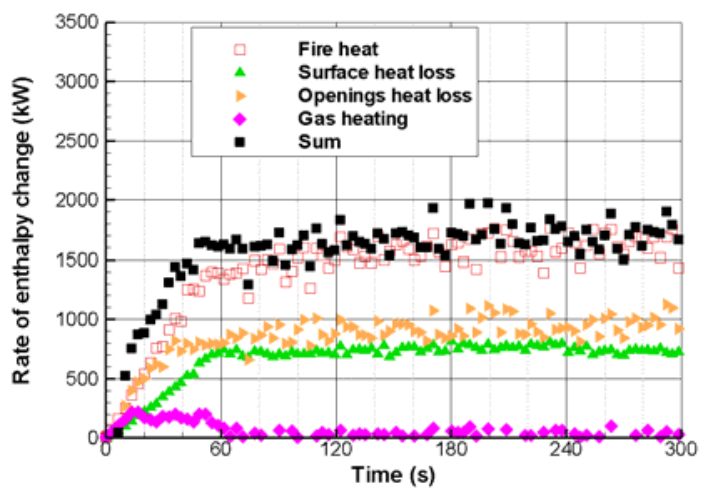

(a)

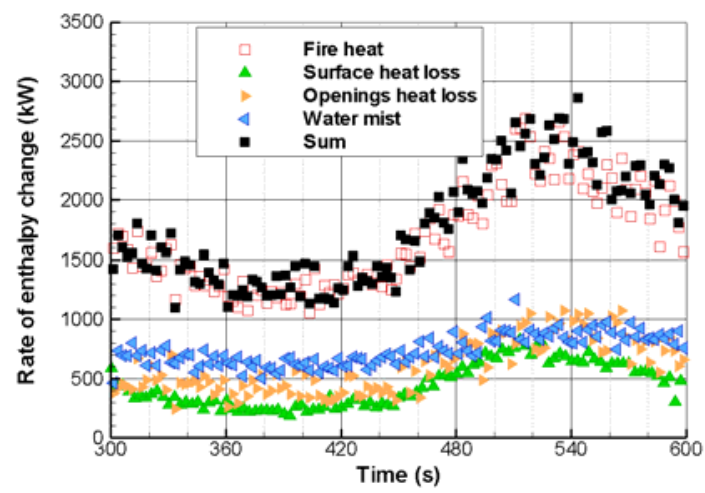

(b)

Fig. 11. Energy balance applied to test tunnel: (a) before water mist activation; (b) after water mist activation.

Droplet contribution has been analyzed more in details. This study is reported on Fig. 12. The distribution is almost constant between 300 and $600 \mathrm{~s}$. The absorbed energy mainly comes from gaseous phase $(73 \%)$. In other words, $73 \%$ of absorbed energy due to droplets induces a gaseous phase cooling. The last $27 \%$ of fire heat absorbed by droplets results from radiation attenuation (18\%) and wall surface cooling ( $9 \%)$.

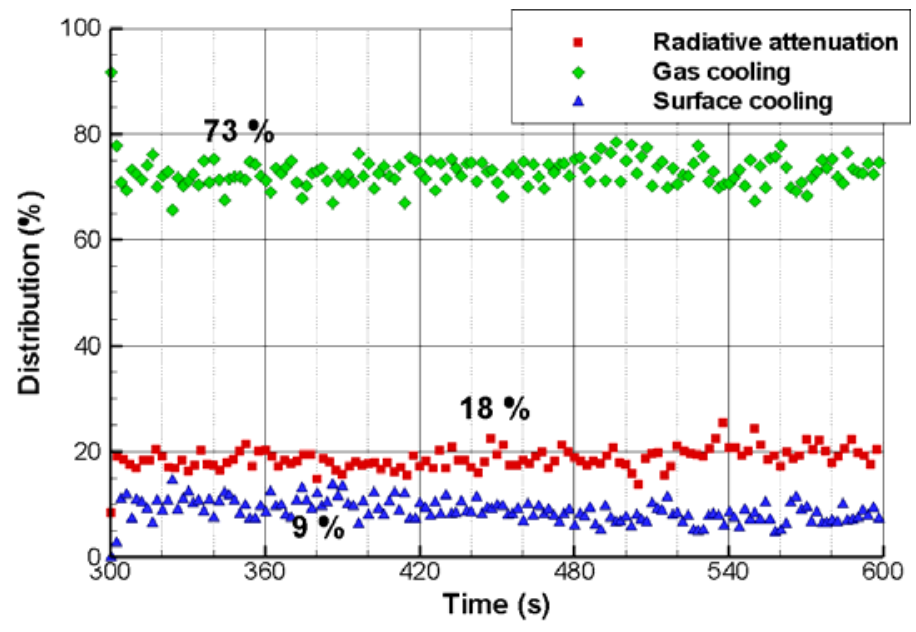

Fig. 12. The rate of absorbed heat by water droplets (radiative attenuation ( $\bullet$ ), gas cooling ( $\bullet)$, and surface cooling $(\boldsymbol{\Delta}))$ versus time.

A part of the heat transferred to each water droplet serves to vaporize it. Energy balance could also be next exploited to determine the water mist system efficiency $\eta$ defined as the absorbed heat by heating and evaporating the water droplets versus the maximum heat that would be absorbed if the whole injected water quantity was evaporated:

$\eta=Q_{p} /\left[\left(L_{v}+C_{p, p}\left(T_{p, \text { evap }}-T_{p, i n j}\right)\right) * \partial\left(m_{p, i n j}\right) / \partial t\right]$

By using the second formulation of the energy balance mentioned above, efficiency has been computed for the present test. The resulting evolution is plotted on Fig. 13. Efficiency varies between 40 and $70 \%$, the time average value over (300-600 s) being $53 \%$. In other words, $47 \%$ of injected water does not absorb energy from gases, wall or by radiation attenuation. 


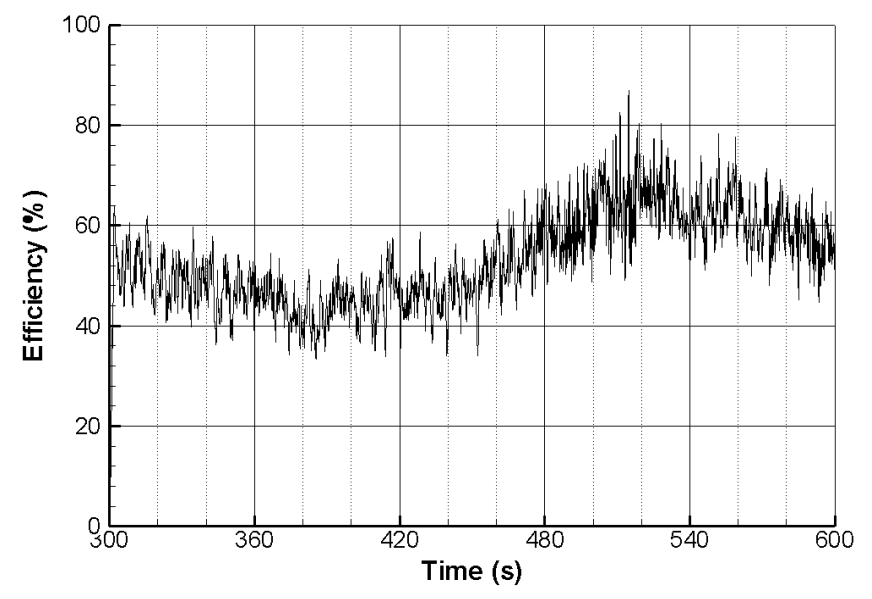

Fig. 13. Water mist system efficiency.

\section{CONCLUSION}

The present article focuses on a better understanding of the interaction between water mist and tunnel fire. For that, the work makes an extensive use of numerical simulation using the FDS (V5.4.0). The approach consists in numerically reconstruct a tunnel fire test interacting with a mitigation system. This test belongs to a campaign conducted in a midscale tunnel (one third scale). It was conducted with a liquid fuel and a high longitudinal velocity which prevents the occurrence of backlayering phenomenon. The use of such scale allows in particular setting up a large number of sensors to well characterize the environment. The discrepancy between prediction by CFD code and measurement has been also assessed, namely in terms of air temperature and heat flux. Moreover, it has allowed determining the relevant numerical parameters to accurately simulate the tunnel fire test. The CFD model has next been used to quantify the global energy balance during the test within the tunnel. For that, some information has been extracted from FDS calculation. After post processing, this has made possible the evaluation of the distribution of energy and in particular the heat absorbed by droplets during water mist application. A definition for water mist system efficiency has then been proposed.

The fire test involving mitigation system has been simulated by mainly setting the longitudinal ventilation flow and HRR versus time. This latter input was set from fuel weight and oxygen consumption monitoring during the all test (even during water mist application). This assumption is important because this input data also considers the fire suppression mechanisms induced by water mist application which concern the fuel and its pyrolysis rate.

The comparison between predicted and measured data has shown that, before mitigation system activation, the overall thermal conditions (temperature and heat flux) are well estimated by the CFD model. In fact, the agreement was around $17 \%$ for temperatures. In comparison with a sub-critical case developed in [15], the agreement seems better when longitudinal velocity is higher than the critical backlayering value. Moreover, a sensitivity analysis has highlighted that this result which concerns the tunnel downstream part, is weakly sensitive to longitudinal velocity. After the water mist activation, the comparison has highlighted that the CFD code predicts the large reduction of air temperature. Until $600 \mathrm{~s}$, the surroundings stay thermally homogeneous on the six temperature measurement sections in the experiment as well as in the simulation.

A global energy balance has been computed within the tunnel. Before mitigation system activation, it has been determined that roughly $50 \%$ of fire heat went to heat tunnel surfaces. The remaining quantity goes into heating of the gases. In comparison with a sub-critical case [15], the energy balance within the tunnel is strongly dependent to the ventilation regime. It results first from the backlayering phenomenon influence and secondly, from the influence of the longitudinal velocity on air temperature in the downstream part of the tunnel [27].

After mitigation system activation, droplets were introduced in fire surroundings inducing gas and surface cooling and radiation attenuation. Energy balance has shown that roughly the half fire heat was also absorbed, the remaining quantity going to heat tunnel surface (24\%) or being convected by hot gases out of 
the tunnel (33\%). Energy absorbed by water droplets mainly comes from gaseous phase $(73 \%)$. The last $27 \%$ of fire heat absorbed by droplets resulted from radiation attenuation (18\%) and wall surface cooling $(9 \%)$.

For practical use, the heat quantity absorbed by water droplets is very important. In fact, in a real tunnel, by reducing in particular the radiative flux, it could improve the operating conditions for firefighters and allow them to be closer to the fire. Moreover, it could prevent fire propagation to other vehicles trapped in the tunnel. Last but not least, by reducing the heat loss rate transferred to boundaries, water mist application could minimize fire damage for tunnel and also reduce the closing duration for reparation. Concerning people that would be evacuating and who are not equipped with thermal and respiratory protection, the present work is not sufficient to say if the egress conditions are improved or not. In fact, toxicity and the lack of visibility are sources of danger for passengers and they are not considered in the present work. Water mist activation could also reduce the fire heat release rate by the three major mechanisms described in the introduction. Until now, the interaction between water mist and fire is tricky to model and it is the subject of few studies.

The present study suggests a definition for the water mist system efficiency. It has been expressed in terms of the water quantity that plays a role in energy balance. This definition has been applied to the midscale fire test. The resulting efficiency has been found to be comprised between 40 and $70 \%$ over the five minutes of water mist application, the time average of the efficiency being $53 \%$. In other words, $47 \%$ of total injected water did not absorb energy from gases, wall or by radiation attenuation.

\section{ACNOWLEDGMENT}

The authors would like to thank the French agency ANRT for the funding of the PhD work during which the present paper was written. The experiment studied in this work was performed within the framework of a research project involving CSTB, CETU, PPRIME Institute and DSC. The authors would also like to acknowledge E. Cesmat who has widely contributed to the mid-scale tunnel project.

\section{REFERENCES}

[1] NFPA 750: Standard on Water Mist Fire Protection Systems, 2010 Edition.

[2] Grant, G., Brenton J., and Drysdale, D., (2000) Fire suppression by water sprays, Progress in Energy and Combustion Science 26: 79-130. http://dx.doi.org/10.1016/S0360-1285(99)00012-X

[3] Dubay, C., and Mawhinney, J.R., (1999) Water Mist Technology Evolves, NFPA Journal 93 (6): 58-65.

[4] Modest, M. F., Radiative heat transfer (2 ${ }^{\text {nd }}$ ed.), Elsevier Academic Press, 2003, p. 263.

[5] Collin, A., Lechene, S., Boulet, P., and Parent, G., (2010) Water mist and radiation interactions: application to a water curtain used as a radiative shield, Numerical Heat Transfer, Part A: Applications 57 (8): 537-553. http://dx.doi.org/10.1080/10407781003744722

[6] Husted, B.P., "Experimental measurements of water mist systems and implication for modeling in CFD”, PhD Thesis, Lund University, 2007, p. 133.

[7] Nmira, F., Consalvi, J.L., Kaiss, A., Fernandez-Pello, A.C., and Porterie, B., (2009) A numerical study of water mist mitigation of tunnel fires, Fire safety journal 44 (2): 198-211, http://dx.doi.org/10.1016/j.firesaf.2008.06.002

[8] Bergqvist, A., Frantzich, H., Hasselrot, K. and Ingason, H., "Fire and rescue operations in tunnel fires: a discussion of some practical issues", The Handbook of Tunnel Fire Safety, Beard, A. and Carvel, R. (ed.), Thomas Telford Publishing 2005, p.481.

[9] Ingason, H., and Lönnermark, A., (2005) Heat release rates from heavy goods vehicle trailer fires in tunnels, Fire Safety Journal 40(7): 646-668. http://dx.doi.org/10.1016/j.firesaf.2005.06.002

[10] Ingason, H., (2008) Model scale tunnel tests with water spray, Fire Safety Journal 43(7): 512-528. http://dx.doi.org/10.1016/j.firesaf.2007.12.002 
[11] Karpov, A.I., Galat, A.A., Novozhilov, V. and Bulgakov, V.K., 2005. Numerical Modeling of the Effect of Fine Water Mist on the Small Scale Flame Spreading over Solid Combustibles. Fire Safety Science 8: 753-764. http://dx.doi.org/10.3801/IAFSS.FSS.8-753

[12] "EUREKA-Project EU 499 FIRETUN, Report on full-scale tests on fires in transport tunnels", Studiensgesellschaft Stahlanwendung, Düsseldorf, Germany 1995.

[13] "Memorial tunnel fire ventilation test program," Interactive CD-ROM and Comprehensive Test Report, Massachusetts Highway Department (1996).

[14] Meyrand, R., “Contribution à l'étude de l'usage du brouillard d'eau dans la lutte contre les incendies en tunnels ventilés longitudinalement". PhD thesis, École Nationale Supérieure de Mécanique et d'Aérotechnique, 2009, p. 288, (available in French).

[15] Blanchard, E., Boulet, P. and Desanghere, S., "Use of computer modelling for the interpretation of midscale tunnel fire test results", Proceeding of Interflam 2010, University of Nottingham, UK, July $5-7,2010$.

[16] Babrauskas, V., Grayson, S.J., Janssens, M. and Parker, W.J., Heat Release in Fires, Elsevier science publishers, 1992, p. 39 and 201.

[17] McGrattan, K., McDermott, R., Hostikka, S. and Floyd, J., "Fire Dynamics Simulator (Version 5), User's Guide", National Institute of Standards and Technology Special Publication 1019-5, Gaithersburg, MD, 2010, 246 p.

[18] McGrattan, K., Hostikka, S., Floyd, J., Baum, H., Rehm, R., Mell, R. and McDermott, R., "Fire Dynamics Simulator (Version 5), Technical Reference Guide, Volume 1: Mathematical Model", National Institute of Standards and Technology Special Publication 1018-5, Gaithersburg, MD, 2010, 124 p.

[19] McGrattan, K. and Hamins, A., "Numerical simulation of the Howard Street tunnel fire, Baltimore, Maryland, July 2001", National Institute of Standards and Technology Report NISTIR 6902, Gaithersburg, MD, 2001, 41 p.

[20] Cochard, S., (2003) Validation of Fire Dynamics Simulator (version 2.0) freeware, Tunnel Management International Journal 6 (4): 32-37.

[21] Mawhinney, J.R. and Trelles, J., "The Use of CFD-FDS Modeling for Establishing Performance Criteria for Water Mist Systems in Very Large Fires in Tunnels", Proceedings of the Third International Symposium on Tunnel Safety and Security, Stockholm, Sweden, March 12-14, 2008.

[22] Trelles, J., and Mawhinney, J.R., (2010) CFD investigation of large scale pallet stack fires in tunnels protected by water mist systems, Journal of Fire Protection Engineering 20: 149-198, http://dx.doi.org/10.1177/1042391510367359

[23] Tewarson, A., "Generation of heat and chemical compounds in fires", The SFPE Handbook of Fire Protection Engineering ( $3^{\text {rd }}$ ed.), DiNenno P.J. (ed.), National Fire Protection Association, Quincy, MA 02269, 2002, p. 3/82.

[24] Ponticq, X., “Études sur les systèmes fixes d'aspersion d'eau en tunnel”. $\mathrm{PhD}$ thesis, Université Claude Bernard - Lyon 1, 2008, p. 234, (available in French).

[25] Hamins, A., Maranghides, A., Yang, J. Donnelly, M., Mulholland, G. and Ohlemiller T., "Report of Test on Experiments for the International Fire Model Benchmarking and Validation Exercise \#3", National Institute of Standards and Technology Special Publication 1013-1, Gaithersburg, MD, 2005, 157 p.

[26] Hamins, A., Johnsson, E., Donnelly, M., and Maranghides, A., (2008) Energy balance in a large $\begin{array}{lllll}\text { compartment fire, Fire } & \text { Safety Journal }\end{array}$ http://dx.doi.org/10.1016/j.firesaf.2007.08.002

[27] Blanchard, E., Desanghere, S., Boulet, P. and Carlotti P., "Energy balance during a midscale tunnel fire test", Proceedings of the Fourteenth International Symposium on Aerodynamics and Ventilation of Tunnels, BHR Group, Dundee, UK, May 11 - 13, 2011. 